\title{
Conceptual machinery of the mythopoetic mind: Attis, a case study
}

\author{
Sándor Darányi ${ }^{1}$ and Peter Wittek ${ }^{1,2}$ \\ 1 University of Borås, Sweden \\ 2 ICFO-The Institute of Photonic Sciences
}

\begin{abstract}
In search for the right interpretation regarding a body of related content, we screened a small corpus of myths about Attis, a minor deity from the Hellenistic period in Asia Minor to identify the noncommutativity of key concepts used in storytelling. Looking at the protagonist's typical features, our experiment showed incompatibility with regard to his gender and downfall. A crosscheck for entanglement found no violation of a Bell inequality, its best approximation being on the border of the local polytope.
\end{abstract}

\section{Introduction}

With Ref. [1] now presenting "quantum information science" to the public, reporting on work in progress, below we look at two of the key phenomena of quantum mechanics (QM), noncommutativity and entanglement.

To contrast Refs. [2-4], Refs. [5] or [6]'s methodological claims, we are interested to find out if conceptual entanglement may be shown outside of a cognitively typical questionnaire or polling scenario, in our case, in classical narratives populating mythologies, with text variants considered as repeated measurements of the same experiment. One of the aforementioned pioneering efforts, Ref. [7] employed four concepts (horse, bear, tiger, cat) in the Animal category vs. four vocal reactions (growl, whinny, snort, meow) from the Act category to create examples of The Animal Acts predicate and have users rank the typicality of the resulting combinations. On the other hand, in the literary analysis we depart from, below we describe our subject matter, The Protagonist Acts, by means of a pair of logical oppositions, one pertaining to the gender of the hero, the other to his downfall. We will use a measurement apparatus akin to the Clauser-HorneShimony-Holt (CHSH) inequality as a decision criterion for detecting nonlocality.

The Protagonist Acts is a popular module used by several narrative genres for plot generation, from classical mythology over heroic legends to fairy tales, cartoons and beyond. The two major ways to formalize narration in the structuralist tradition are Refs. [8] and [9], with a possible middle-of-the-road approach provided by Ref. [10]'s monomyth theory, aided by a comprehensive motif inventory by Ref. [11], and a canonical tale type catalog by Ref. [12]. Taken together, these preliminaries necessitate a modelling approach which may or may not fall back on genomics [13]. 
In the current paper, we will focus on a different question though, looking at the type of the "conceptual glue" holding related content together, admittedly trying to go beyond standard statistical concepts, and will screen a small corpus of Hellenistic myths for order-dependent observations and possibly entangled concepts related to gender and destiny. We aim to demonstrate the following:

- Incompatibility of measurements, leading to noncommuting observations;

- As not all measurements are incompatible, we can partition them into commuting fractions. In the terminology of information theory, we can label the resulting two partitions as Alice and Bob. The measurements within a party do not commute, but they do so between the parties;

- In this setup, we try to demonstrate the violation of a Bell inequality, which would be a curious instance of superclassical correlations in the context of folklore research.

Below we are able to argue the noncommutativity of observations on the gender and destiny of Attis, but a Bell violation remains elusive.

\section{Background}

Mythology is a universal phenomenon in old cultures worldwide. For this paper, we define it as the first systematic attempt of thinking about the origins of the world and its beings, their existence and fate, told by series of stories in first oral, then written tradition. Typically, such considerations address creation in primordial times vs. legendary or prehistoric times from the vantage point of the storyteller, the first phase dealing with the divine aspect of things becoming, the second with their semidivine unfolding, due to heroes, tricksters and other kinds of mediators between heaven and earth.

Classical mythology refers to the often syncretic plethora of Greek and Roman stories about the gods, heroes and humans, including the origins of social institutions and moral conduct. As difficult as it is to assign a starting date to classical myths, with regard to the selected type of deity below, the so-called dying god, the concept could span a long period, e.g. from 3000 B.C. up to Hellenistic times, and cover an area much beyond classical Greece and the Mediterranean, including the Ancient Near East.

In this enormously big cultural space, over the millennia different interpretation attempts tried to come up with coherent explanations of mythic content. Their overview is the subject of many books, so let it suffice here to mention only a few prominent schools and their representatives in chronological order. We can distinguish between the allegorical theory from the ancient, in a sense leading to the symbolic theory through the Middle Ages and up till the 19th century; then again, rationalism and euhemerism in classical antiquity, to be followed by a theory of nature myths in the 19th century, itself based in then new comparative philology, leading to a spectrum of competing modern methods. These include e.g. the ritual school (e.g. Frazer, Harrison), the social study of myth (Durkheim, Mauss), the philosophy of symbolic forms and the myth of the 
state (Cassirer), psychological analysis (Jung, Hillmann), different directions in anthropology (Malinowski, Leach, Lévi-Strauss, Maranda), or the combination of structural anthropology with multivariate content analytics [14].

From our perspective, in what follows mythology will be a classification tool for the savage mind [15], using an attenuating series of logical oppositions to compromise between normative extremes by mediation, so that the process manifests itself as a chronological sequence of text variants of related but different content by different communities or authors. Thus whereas such variants are expected to "somehow" belong together and manifest a gradually progressing pattern of mythological text cycles organized between highly complex conceptual poles [16], the very nature of this "somehow" is a matter of investigation. Here, conceptual correlations are being considered as one particular type of intellectual linkage among text variants about the same gross topic, fertility, and discussing the same hero, Attis.

Once widespread in the Mediterranean and the Ancient Near East, the fertility myth is a symbolic prescription of how to restore individual and community welfare. Briefly, proper moral conduct being the key, disaster strikes due to ill behaviour or violation of social norms, whereas the role of the regulator (a male or female deity or a human, such as a sacred king or queen) is to remedy the insult to the supernatural, and thereby bring back fertility, an indicator if things are on the right track.

Lately we have shown how to insert narrative elements manifesting specific grammatical categories into the term and function slots of the canonical formula of myth proposed by Ref. [17], demonstrating its workings on a set of myths about flower heroes and minor deities from Ancient Greece and Asia Minor in the Hellenistic period [14]. These mythic actors belong to the family of dying gods, a category in comparitive religion whose presence and absence relates to the virulence and decay of e.g. vegetation, and in the broadest sense, fertility [18]. Our prime example for this treatise, the Phrygian Attis is one of them, being the consort of Cybele, the Magna Mater, a variant of the Mediterranean Great Goddess whose cult was imported to Rome in 205-204 BCE. The plot in shorthand is close to the Adonis myth: a youth either sacrifices his virility to the goddess or is punished by her to the same end, both outcomes leading to the restoration of natural and/or social well-being. ${ }^{3}$

With Attis as our actor in The Protagonist Acts statement, we depart from the working assumption that this predicate contains the following mutually exclusive elements encoded in its state: [gender group: male, androgynous (= of double gender, bisexual), asexual] x [action modifier group: (indirect vs. direct)

\footnotetext{
${ }^{3}$ Stories about the fate of Attis, Adonis and other minor deities explain the origins of certain flowers and trees. However, the violet, the anemone, the hyacinth, the daffodil, or the pine tree have no agricultural significance, so one has to consider them as efforts to restore fertility on a more abstract level, such as invoking the arrival of spring or addressing the annual solar cycle. Social welfare as a concern is attested by the fact that Attis has an explicit cult, passed on between regional communities, finally imported to the capital of the empire.
} 
vs. (self vs. not self)]. To wit, in the majority of available text variants, in the final chapter of his story Attis emasculates himself (direct self-mutilation [DS]); or they mutually castrate each other with his partner (not-direct self-mutilation [NDS]); alternatively he is killed by a spear or an unspecified wound on boar hunting (not-direct not-self-mutiliation [NDNS], i.e. killing by accident or similar); and in some cases, it is the goddess who mutilates him (direct not-selfmutilation $[\mathrm{DNS}])$.

Below we will focus on gender and downfall as measurements made by Alice and Bob, our two pieces of independent recording apparatus, so that their interpretation of the running text will play the role of the recorded values. The reason why interpretation matters is that these texts, considered as our corpus, are contradictory with regard to the outcome and therefore the general impression about the protagonist is that of ambiguity. In other words, with interpretation in the eye of the beholder, we do not expect individuals to come to the same conclusions. More detail about this is given below.

\subsection{The ambiguity about Attis}

A typical plot of a flower aetiology myth, from Pausanias' Description of Greece, helps one understand the context where ambiguity regarding the protagonist's gender on corpus level renders his canonical interpretation difficult. The story originally seems to have followed a cyclic pattern, probably both symbolizing and reinforcing the annual cycle of the vegetation, starting with an androgynous or purely male donor who passed on the male principle to a female receiver, who in turn gave birth to, or became the origin of, another androgynous or male offspring, itself or himself the next donor. In Pausanias' reporting, respective subject-verb-object (SVO) propositions in active or passive voice for narration (i.e. for building concatenated statements) are as follows: Papas drops semen; semen is dropped ( = falls) to earth = earth absorbs semen; semen impregnates Agdos; Agdos becomes = bears Agdistis; Agdistis drops virility; virility impregnates earth; earth bears tree; tree drops fruit; fruit impregnates Nana; Nana bears Attis; Attis drops virility; virility impregnates earth; earth bears flower. Here, Papas is the sky-god; earth is the Great Goddess, personified by the mountain Agdos; Agdistis is their androgynous offspring with an uncontrollable, devastating nature which needs to be "regulated"; and Nana is a sacred princess or a priestess, i.e. the personification of the Goddess with a penchant for unusual conception, at least from a human perspective. Tree, fruit and flower are variables that can take different values as the plot thickens.

With the number of surviving text variants somewhere between 20-25, of which we used 20 in the current attempt, given the above small cycle of myths about violating social norms and mending them by mutilation as a compensation for the crime, the first and strongest impression one is left with after having read them is that of confusion. Namely, in spite of the dramatic peak of the narrative culminating in his castration, the gender of the hero is sort of unstable, and seems to be oscillating between three alternatives out of four. The presentation of Attis as a male (in most of the sources), or an eunuch ("neither male nor 
female" in Hermesianax), is easy to document. Further, clearly, he cannot be a female, although implicit in the situation, the act of mutilation brings the state of the quasi-female dangerously close. But the missing link to understand the big picture in its complexity is the fourth alternative, the concept of divine androgyny, of Semitic origins [19, p. 218], which - in support of Rapp on Kybele in [20] - Hepding identifies with the tendencies of the Phrygian variant, and refers to the Neoplatonic speculations of Iulian for a parallel [19, p.212]. The other source who describes Attis as a hermaphrodite, i.e. a being of both genders, is Hippolytus.

In this androgynous context, castration or emasculation have several interpretations, one of them being a positive move toward the perfection of the Great Mother - a man who cannot become a woman can still go halfway by rendering himself a non-male. Another one is the punishment for abandoning chastity sworn to the deity, inducing some sort of an artificial replacement state by getting rid of sin. More importantly, this latter explanation has a second layer of meaning: losing one's virility is a prevention of creative excess aiming at male dominance, a kind of hybris. This perspective is familiar from the story of Aphrodite whose birth was a result from Ouranos' castration, caused by his unruly behaviour toward Gaia, i.e. his non-diminishing urge to procreate, apparently upsetting world order to that extent that Kronos had to intervene and tame the sky-god, or risk increasing disorder.

On the other hand, Gaia - another name for the Great Goddess - has the archaic capability of procreating "without sweet union of love" (i.e., by parthenogenesis), thus giving birth to Ouranos the sky, Pontos the sea and Ourea the mountains as the firstborn of the ancient deities (Hesiod Theogony 129-132). This capacity is also passed down to the dominant goddesses of the next two generations, first to Rhea, then to Hera. ${ }^{4}$ Howev er, such creative acts without male intervention imply another interpretation too, namely that the primordial goddess inherently possesses the male principle as well, hence her husband's or partner's redundancy, a rendering that brings us back to androgyny.

As we will see, these fragments are pieces of a puzzle that will become important below when we recognize in them the key to e.g. Iulian the Apostate's Gnostic explanation of Attis' role in the universe, one of our androgynous examples. The same holds for Hippolytus' account who refuted Gnostic heresies and thereby preserved for us a comparable story in shorthand. But before we proceed, it's time to explain how we want to check if conceptual entanglement or its components are present in our sample.

\footnotetext{
${ }^{4}$ Hera, queen of the gods, was outraged by Zeus' ability to procreate Athene by himself and, in revenge, she conceived the dragon Typhaon by hitting on the ground (Homeric hymn to Apollon 309). Flora, here Rhea's Latin equivalent, helped Juno, i.e. Hera, fall pregnant by touching her either with a magic herb (Festus Grammaticus 97), or a flower (Ovidius Fasti 5, 229), both being parallels to Nana's miraculous pregnancy by an almond. Out of this fatherless conception resulted the monstruous Ares, i.e. Mars, the god of war.
} 


\section{Measurements in the context of mythological texts}

If we aspire to study classical and potentially nonlocal correlations in myths, we must consider the act of text interpretation - a.k.a. hermeneutics - as measurement. Just like no incompatibility or entanglement has ever been detected without measuring some system properties beforehand, no interpretation can result without having read the text first.

\subsection{Material and method}

The following sources were consulted: Pausanias Description of Greece VII, 17; Hermesianax in Pausanias VII, 17, 9; Herodotus History I, 34-45; Lucianus De Dea Syria c. 15; Arnobius Adversus Nationes V, 5; Diodorus Bibliotheca Historica III, 58; Ovidius Fasti IV, 221; Fulgentius Mitologiarum Libri III, 5; Minucius Felix Octavius 22; Servius Scholia ad Aeneidem IX, 115; Arnobius' Source 2 (Valerius Pontifex in Hepding 1903:118); Iulianus Orationes V; Sallustius De Diis et Mundo 4; Hippolytus Refutation of All Heresies 5; Theophilus of Antioch To Autolycus 8; Eusebius of Caesarea Praeparatio Evangelica II, 43; Clemens Alexandrinus Exhortation to the Heathen 2; Tatian Address to the Greeks 8; Augustine City of God 6, 7; and Catullus 63. Tertullianus and Valerius Flaccus were left out this comparison because they have information about the gender of Attis only bu t not his downfall.

To decide if incompatibility can affect such feature-based measurements, we designed a limited set of scenarios for texts with multiple possible interpretations in our sample. These texts were Servius, Herodotus, Iulianus and Hippolytus. After preliminary screening, we focused on the scenario where Attis' gender was androgynous in heaven and male on earth, as in the Gnostic accounts ${ }^{5}$, whereas the type of downfall was concurrently DNS (antagonist harms protagonist) and NDS (antagonist and protagonist mutually harm each other).

Based on the sample, we shall be working toward a Bell scenario which means that one party will have two two-output measurements, whereas the other party has two three-outcome measurements. In doing so, for transparency reasons, we recall the following line of thought in our experiment design:

- Texts which contain conflicting information about gender and downfall seem to suggest that incompatibility is to be associated with the reader and not the text. However, on one hand, with the number of available variants strictly limited, one cannot exclude such sources without weakening the statistical basis of findings. On the other hand, incompatibility - just like any conceptual content - is in the eye of the beholder, as texts do not contain concepts, only their written imprint which resonates in the reader in unspecified ways.

\footnotetext{
5 The underlying assumption here is that two text variants with contradictory content may have merged into a syncretic new one from a historically more complex perspective. This is why, in spite of the mutually exclusive gender features, we did not decompose such texts into shorter hypothetic fragments but retained them as they were for analysis, thereby violating the exclusiveness assumption.
} 
Incompatibility as we base it on the act of interpretation is the sum total of respective decisions of the observer, i.e. the result of measurement, but this interpretation depends on the occurrence of certain concepts in the text;

- In experimental tests of the Bell inequalities a key issue concerns the "fair sampling" assumption. Essentially this presupposes that the detected events constitute an unbiased sample of the particles emitted. For the analysis of text variants one would need to assume firstly that writers are no more likely to record versions of the myth that contain certain features, and that texts containing certain features are no more likely to have survived, because if e.g. authors preferred to record versions of the myth where Attis was male, or these versions were somehow more likely to have survived, this would change the analysis.

But what does an unbiased sample mean with respect to mythology? For one thing, the size of the set is constant because those who could have penned down new conceptual variants are all dead. Also, we can assume that no new versions will surface (unless a new Nag Hammadi library will be found etc.). On the other hand, one cannot make sure whether any of the recorded variants had preferences for gender or downfall at the time of being written up, although it's fair to suspect that authors had certain belief systems they contrasted with the by then recorded beliefs to take a stance. But this is a situation one cannot help, not even on the level of speculation. So one could suggest that this could be a potential problem of sampling after one had proven that the bias was there at the time of recording, which is absolutely impossible, a limitation of the method we must be aware of.

\section{$3.2 \quad$ Incompatibility}

Interpretation is always a matter of preconception. In our case, stories about Attis are contradictory as a corpus because of uncertainties about his gender, leaving room for speculations. And nowhere else more so than in Iulian's text which now placates him as probably androgynous, then elsewhere as predominantly male. Which communication shall we believe? What we hope to show is that it depends on the different impressions one gains by looking for one or the other alternative in the first place. This assumes ambiguous episodes in the narratives, hence we depart from Ref. [21].

Our first aim will be to demonstrate that these two measurements do not commute. In the language of information theory, let us now focus on one party first, Alice. As said, she has two two-output measurements, so one measurement means a pair of oppositions. A simple setup, for instance, is the following (Table 1):

- Alice's first measurement $(x=0)$ : male $(a=0)$ or not male $(a=1)$;

- Alice's second measurement $(x=1)$ : androgynous $(a=0)$ or not androgynous $(a=1)$.

Since female never occurs in any of the text variants, we can regard the not male as meaning eunuch. 


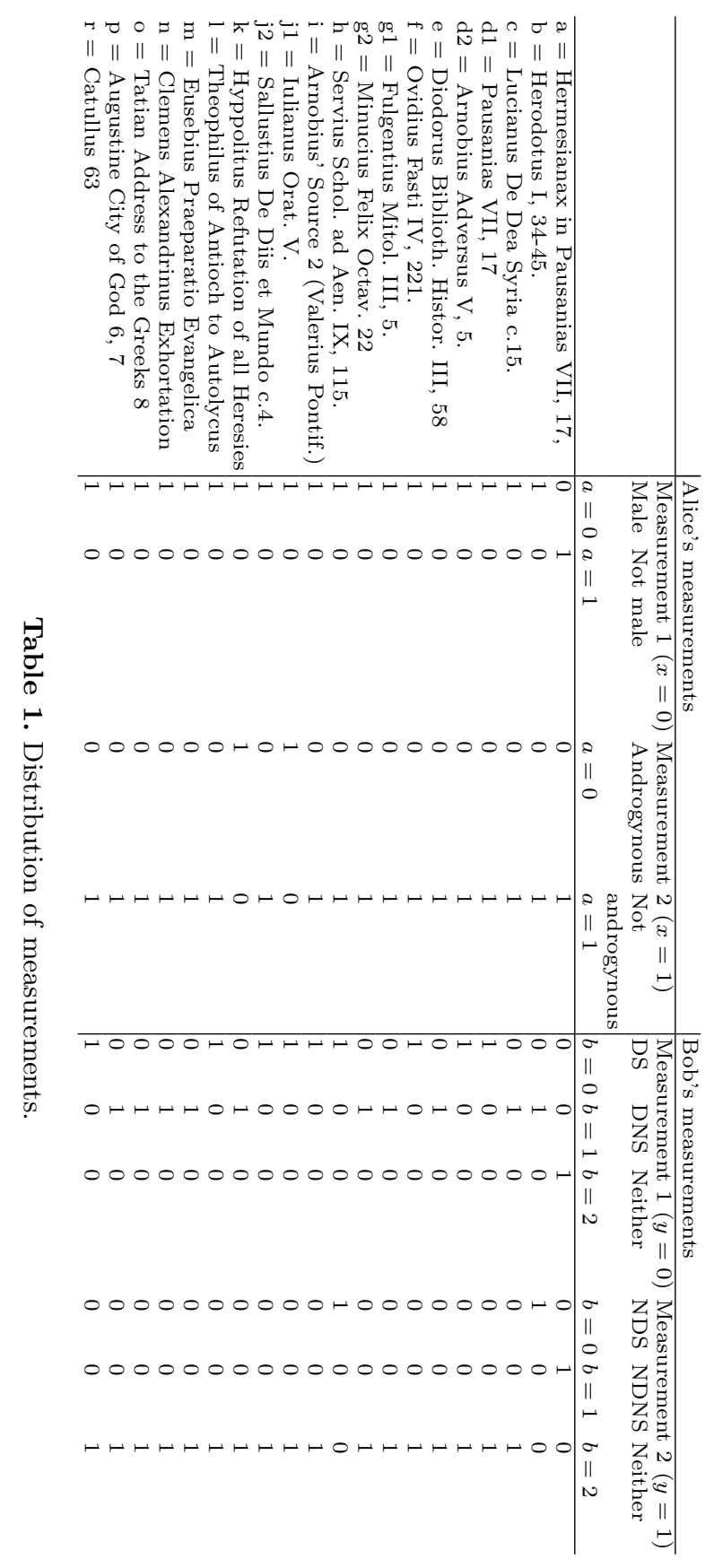


Starting with clues which present Attis as a man will reinforce this impression by a number of references in the text, and somehow downplay the other option. Likewise, looking for androgyny will result in an impression of the same structure, i.e. belief vs. disbelief. However, our point is that the proportions of the two downplayed alternatives will be different, and this difference cannot be traced back anywhere else but to the context, i.e. the sequence of measurements invoking non-commutativity. In this sense, we postulate that conceptual incompatibility comes with the coexistence of conflicting interpretations pertaining to the same source, and the dominant impression is proportional to the respective occurrences of the rival concepts - if we focus on the androgynous features first, and find e.g. 2 of them, whereas for a next step Attis' male nature is recorded e.g. 19 times, then 2/19 expresses something about this impression. In reverse order, 19/2 would state our confidence about Attis being a man rather than someone of a double nature.

Demise of the hero is another aspect of the narrative where incompatibility seems to be at work. To show this, we define two three-output measurements as follows:

- Bob's first measurement $(y=0)$ : direct self $(b=0)$, direct not-self $(b=1)$, or neither $(b=2)$.

- Bob's second measurement $(y=1)$ : not-direct self $(b=0)$, not-direct not-self $(b=1)$, or neither $(b=2)$.

E.g. in Herodotus, Attis is killed by Adrastos' spear in a hunting accident, who in turn kills himself on his grave. Depending on where we want to lay stress, one can read this as mutual downfall of an accidental protagonist and his like antagonist where the other and the self are just aspects by which death arrives; or one can focus on the self in the suicide and the other in the accident as key aspects, rendering both involuntary downfalls as secondary. Hence both, contradictory readings must be recorded for measurements. Not much different is the text of Servius: there, Attis is a youth who flees his king, the antagonist willing to rape him, but they end up in castrating each other. To commemorate her hero, the Magna Mater orders his priests to ritually mutilate themselves. Without this rite as the conclusion of the story, the protagonist and antagonist mutually harming each other is the single outcome; however, with the rite, an alternative is to stress the voluntary self -punishment aspect repeated annually at the summer solstice. Again, we have to record both contradictory interpretation options.

\section{Studying correlations}

Our argument for the availability of a Bell test is that given a single narrative (or a set of narratives) with two typical elements, e.g. gender and downfall, in a time-like separation scenario, their correlation can be detected, i.e. we realize that these elements co-occur in the same story or corpus, alongside the same plot. Space-like separation here means that we assume two single concept queries, Alice and Bob, with no feedback between them. This, of course, has no physical 
meaning. It simply means that the information about gender has no influence on information about downfall. A retrieved concept is represented by a group of two logical oppositions, each of which are manifest by a set of related terms. Alice and Bob's measurements on their separated concepts will reveal by their joint probabilities if the concepts are linked in a way beyond simple term-level co-occurrence.

Therefore to study correlations between Attis' gender and his demise, we treat the two-party measurements as a Bell scenario. Alice has a pair of twooutput measurements, whereas Bob has a pair of three-output measurements, so we can briefly write this as a [(2 2) (3 3)] scenario. This is clearly different from the CHSH test, which is [( $\left.\begin{array}{l}2 \\ 2\end{array}\right)$ (2 2)]. As Ref. [22] proved, the two correspond to the same polytope, the [( $\left.\left.\begin{array}{lll}2 & 2\end{array}\right)\left(\begin{array}{ll}3 & 3\end{array}\right)\right]$ scenario is a lifting of the CHSH case. With the measurement distribution given in Table 1, we perform an analysis of the CHSH inequality.

Since in the Collins-Gisin notation we can ignore one output, we have a certain degree of freedom in choosing which outputs we include in the Bell test. We choose $a=0$ from $x=0, a=1$ from $x=1, b=1$ from $y=0$ and $b=1$ from $y=1$. While this choice is arbitrary, a Bell violation would show in any choice of outputs from the measurements. The joint probabilities $p(a b \mid x y)$ are given in Table 2 .

With this configuration, we find a value of 2.0 for the inequality, which indicates no violation, but the observed correlations are on the margin of the local polytope.

\begin{tabular}{|c|c|c|c|}
\hline & \multicolumn{3}{|c|}{$x=0 x=1$} \\
\hline & 1. & 0.95 & 0.05 \\
\hline$y=0$ & 0.5 & 0.5 & 0 \\
\hline$y=1$ & 0.05 & & 0.05 \\
\hline
\end{tabular}

Table 2. Joint probabilities of the measurements

\section{Conclusion and future research}

On a collective level, myths are classificatory structures, using a system of logical oppositions. The prevalence of opposites indicates the possibility for conceptual entanglement in general. The current case study has shown the noncommutativity of observations on the gender and destiny of Attis, but a Bell violation remained elusive. This may go back to an incomplete working hypothesis, the sample size, the odd nature of the current data - some options e.g. "not male" or "NDNS" almost never appear -, or a combination thereof. In spite of its expected increase in complexity, the results presented here pave the way for an extended case study with more actors and types of action where we plan to compare more sophisticated interpretation scenarios. 
Further, a challenging implication of Ref. [23] adds a new perspective to looking for entanglement in myths as follows:

- Classical mythology stopped to evolve, so for an external observer with an external measurement device, two concepts inside the system may appear as dislocated yet the same, with no metric differences a.k.a. change between them, being entangled;

- For a parallel observer inside the system, who measures evolution in terms of two entangled concepts with regard to the rest of the universe, the same two concepts are perceived as dislocated, with metric differences, change and chronology separating them;

- Occasionally both observation modes may be available to the mind, perhaps related to subjective vs. objective experience.

\section{Acknowledgement}

This project has received funding from the European Union's Seventh Framework Programme for research, technological development and demonstration under grant agreement no FP7-601138 PERICLES. PW would like to thank Alexia Salavrakos for the discussions on Bell inequalities. The authors are grateful to two unknown reviewers plus Roger Pearse's blogs on antiquity and his links to translations. ${ }^{6}$ Other classical sources were used from the Perseus Digital Library. ${ }^{7}$

Dedicated to the memory of Hugo Hepding (1878-1959), classical philologist, ethnographer and librarian.

\section{References}

1. Bawden, D., Robinson, L., Siddiqui, T.: "Potentialities or possibilities": Towards quantum information science? Journal of the Association for Information Science and Technology 66(3) (2015) 437-449

2. Aerts, D., Aerts, S., Broekaert, J., Gabora, L.: The violation of Bell inequalities in the macroworld. Foundations of Physics 30(9) (2000) 1387-1414

3. Aerts, D., Gabora, L.: A theory of concepts and their combinations I: The structure of the sets of contexts and properties. Kybernetes 34(1/2) (2005) 151-175

4. Aerts, D., Gabora, L.: A theory of concepts and their combinations II: A Hilbert space representation. Kybernetes 34(1-2) (2005) 192-221

5. Aerts, D., Broekaert, J., Sozzo, S., Veloz, T.: Meaning-focused and quantuminspired information retrieval. In Atmanspacher, H., Haven, E., Kitto, K., Raine, D., eds.: Proceedings of QI-14, 8th International Conference on Quantum Interaction. Volume 8369 of Lecture Notes in Computer Science., Springer Berlin Heidelberg (June 2014) 71-83

\footnotetext{
${ }^{6}$ http://www.roger-pearse.com/weblog/

7 http://www.perseus.tufts.edu/hopper/
} 
6. Aerts, D., Sozzo, S.: Entanglement zoo I: Foundational and structural aspects. In Atmanspacher, H., Haven, E., Kitto, K., Raine, D., eds.: Proceedings of QI-13, 7th International Quantum Interaction Symposium. Lecture Notes in Computer Science, Springer Berlin Heidelberg (2014) 84-96

7. Aerts, D., Sozzo, S.: Entanglement zoo II: Examples in physics and cognition. In Atmanspacher, H., Haven, E., Kitto, K., Raine, D., eds.: Proceedings of QI-14, 8th International Conference on Quantum Interaction. Volume 8369 of Lecture Notes in Computer Science., Springer Berlin Heidelberg (June 2014) 97-109

8. Propp, V.: Morphology of the Folktale. University of Texas Press, Austin, TX, USA (1968)

9. Lévi-Strauss, C.: Structural Anthropology. University of Chicago Press, Chicago, IL, USA (1983)

10. Campbell, J.: The hero with a thousand faces. Volume 17. New World Library (2008)

11. Thompson, S.: Motif-Index of Folk-Literature 1-6. Indiana University Press (1958)

12. Uther, H.: The types of international folktales: A classification and bibliography based on the system of Antti Aarne and Stith Thompson. Academia Scientiarum Fennica, Helsinki, Finland (2004)

13. Ofek, N., Darányi, S., Rokach, L.: Linking motif sequences to tale type families by machine learning. In: Proceedings of CMN-13, 4th Workshop on Computational Models of Narrative. (2013)

14. Darányi, S., Wittek, P., Kitto, K.: The Sphynx's new riddle: How to relate the canonical formula of myth to quantum interaction. In: Proceedings of QI-13, 7th International Quantum Interaction Symposium. (July 2013) 47-58

15. Lévi-Strauss, C.: Mythologiques I-IV. Plon, Paris, France (1964-1971)

16. Darányi, S.: Formal aspects of natural belief systems, their modelling and evolution: A semiotic analysis. Semiotica 108(1) (1996) 45-63

17. Lévi-Strauss, C.: The structural study of myth. In: Myth: A Symposium. Indiana University Press (1965) 50-66

18. Frazer, J.: The Golden Bough: A Study in Magic and Religion. A Touchstone Book. Simon \& Schuster (1995)

19. Hepding, H.: Attis: seine Mythen und sein Kult. ATLA Monograph Preservation Program. J. Ricker (1903)

20. Roscher, W.: Ausführliches Lexikon der griechischen und römischen Mythologie: Laas - Myton. Number 2. k. Teubner (1993)

21. Bruza, P., Woods, J.: Quantum collapse in semantic space: interpreting natural language argumentation. In: Proceedings of QI-08, 2nd International Symposium on Quantum Interaction, Oxford, UK (March 2008)

22. Pironio, S.: All Clauser-Home-Shimony-Holt polytopes. Journal of Physics A: Mathematical and Theoretical 47(42) (Oct 2014) 424020

23. Moreva, E., Brida, G., Gramegna, M., Giovannetti, V., Maccone, L., Genovese, M.: Time from quantum entanglement: An experimental illustration. Physical Review A 89(5) (May 2014) 